\title{
Killi Zeminler Üzerindeki Yol Dolgularında Konsolidasyonun Hızlandırılması
}

\author{
${ }^{1}$ Recep Akan, ${ }^{* 2}$ Sedat Sert ve ${ }^{2}$ Ertan Bol \\ ${ }^{* 1}$ Mühendislik Fakültesi, İnşaat Mühendisliği Bölümü, Süleyman Demirel Üniversitesi, Türkiye \\ ${ }^{2}$ Mühendislik Fakültesi, İnşaat Mühendisliği Bölümü, Sakarya Üniversitesi, Türkiye
}

\begin{abstract}
Shortening of the consolidation time of road fills built on soft soils is an important problem and design factor. In this study, the consolidation time and dissipation of excess pore pressures were examined for both natural and vertical prefabricated drains improved soft soil by finite element analyses. Analyses were done with Plaxis 2D software which is used for two dimensional analyses of deformation and stability problems in geotechnical engineering.
\end{abstract}

Key words: Soft soil, road embankment, consolidation, vertical prefabricated drains.

\section{Özet}

Zayıf zeminler üzerinde inşa edilen yol dolgularında konsolidasyon süresinin kısaltılması önemli bir problem ve tasarım faktörüdür. Bu çalışmada doğal zeminler ve prefabrik düşey drenlerle iyileştirilmiş zeminlerde konsolidasyon süresi ve ilave boşluksuyu basınçlarının sönümlenmesi sonlu eleman yöntemiyle incelenmiştir. Analizler geoteknik mühendisliğinde deformasyon ve stabilite problemlerinin iki boyutlu analizi için kullanılan Plaxis 2D yazılımı ile gerçekleştirilmiştir.

Anahtar kelimeler: Zayıf zemin, yol dolgusu, konsolidasyon, düşey dren.

\section{Giriş}

Yumuşak zeminler üzerine yapılacak dolgular birçok araştırmacının yıllardır üzerinde çalıştı̆̆ bir zemin mekaniği problemidir. Yıllardır yapılan araştırmalar ve edinilen tecrübelere rağmen günümüzde bu konu, temel zemininin zayıflığı nedeniyle değişik sorunlar ortaya çıkarmaktadır. Bunlardan bazıları zeminin zayıflığından dolayı güvenli taşınabilecek yük sınırının düşük olması, bir diğeri de yüksek şekil değiştirebilirlik ve düşük geçirimlilik nedeniyle yüksek konsolidasyon oturmalarının çok uzun sürelerde meydana gelmesidir [1].

Yumuşak zemin üzerine yapılan dolguların tasarımında birden fazla etken dikkate alınmaktadır. Yumuşak zeminin konsolidasyonunu tamamlayabilmesi için gerekli zamanın nasıl en aza indirileceği konusu bu tasarımda en etkili faktörlerden biri olmaktadır. Prefabrik düşey drenler (PVDs), konsolidasyonun hızlandırılması ve gerekli bekleme süresinin kısaltılması amacıyla kullanılan yöntemlerin başında gelmektedir [2, 3, 4, 5]. Prefabrik düşey drenler, yumuşak zeminlerin geçirimliliğinin büyük mertebelerde artışııı sağlamaktadır [6, 7].

*Corresponding author: Address: Faculty of Engineering, Department of Civil Engineering Sakarya University, Sakarya TURKEY. E-mail address: sert@sakarya.edu.tr, Phone: +902642955738 
Dolgu yükü altındaki prefabrik düşey drenler ile iyileştirilmiş yumuşak alt zeminlerin davranışını incelemek için genellikle sonlu elemanlar analizi kullanılmaktadır. Borges (2004), yumuşak zemin üzerine inşa edilen dolgunun üç boyutlu davranışını incelemiş ve analizlerini Biot'un konsolidasyon teorisini dikkate alan sonlu eleman modeli ile gerçekleştirmiştir [1]. Araştırmacı, analizleri hem düşey drenli hem de düşey drenlerin olmadı̆̆ı durum için gerçekleştirerek inşaat süresi ve sonrasında ilave boşluk suyu basınçları, düşey oturmalar, yatay yer değiştirmeler ve gerilme seviyelerini incelemiştir. Sonuç olarak düşey dren kullanımının toplam konsolidasyon süresini 10 kata kadar azalttığı, inşaat süresinde gerçekleşen oturmayı belirgin derecede artırdığı ve ilave boşluk suyu basınçlarının sönümlenmesini hızlandırdığı ortaya konmuştur.

Shen ve ark. (2005), biri prefabrik düşey drenler ile iyileştirilmiş, diğeri ise iyileştirilmemiş iki farklı durumu eşdeğer düşer geçirimlilik yaklaşımı ile değerlendirmiş ve dren kullanımının etkisini irdelemişlerdir [8]. $19 \mathrm{~m}$ uzunluğunda düşey drenleri $1.5 \mathrm{~m}$ aralıklarla yerleştirmişler ve düşey dren kullanımının yumuşak zeminin geçirimliliğini 30 kat artırdığını, ilave boşluk suyu basınçlarının çabuk şekilde sönümlenmesini sağladığını ortaya koymuşlardır.

Lo ve ark. (2008), geogrid ile güçlendirilmiş ve düşey drenlerle takviye edilmiş bir yol dolgusunun uzun süreli performansını incelemişlerdir [9]. Araştırmacılar, arazideki ilave boşluk suyu basıncını, toprak basıncını ve dolgu tabanına serilen geogridde meydana gelen çekme gerilmelerini 400 gün boyunca ve oturmaları 9 yıl boyunca takip etmişledir. İlave boşluk suyu basınçlarını ve oturmaları tahmin edebilmek için birim hücre sonlu elemanlar analizini kullanmışlar ve sonuçları gerçek ölçüm değerleriyle karşılaştırmışlardır. Tahmin edilen ilave boşluk suyu basınçları gerçek ölçüm değerleriyle uyum gösterirken, dolgunun merkezi için tahmin edilen oturmalar gerçek ölçüm değerlerinden daha küçük değerlerde elde edilmiştir.

$\mathrm{Bu}$ çalışmada, prefabrik düşey drenlerin kullanımının yol dolgusu altında kalan yumuşak temel zemininde meydana getireceği davranış değişikliğini belirleyebilmek için aynı yol inşaatı modeli hem prefabrik düşey drenler kullanılarak hem de prefabrik düşey drenler olmadan zeminin doğal durumuyla analiz edilmiştir. Analiz sonuçlarına göre prefabrik düşey drenlerin zeminde meydana gelecek ilave boşluk suyu basınçlarına ve zeminin konsolidasyonunu tamamlaması için gerekli süreye etkisi yorumlanmıştır.

\section{Materyal ve Metot}

Hipotetik model üzerine kurulan bu çalışma kapsamında, 6 metrelik yol dolgusunun çok düşük geçirimliliğe sahip kil zeminler ve düşük sayılabilecek geçirimlilikteki kumlu kil/killi kumları içeren bir kesitin üzerine yapılması durumunda meydana gelecek ilave boşluk suyu basınçları ve konsolidasyonun tamamlanması için gerekli süre incelenmiştir. Dolgunun yapılacağı zemin kesiti en üstte $6 \mathrm{~m}$ kil tabakası ve aşağı doğru sırasıyla $2 \mathrm{~m}$ kum tabakası, $5 \mathrm{~m}$ kil tabakası ve $10 \mathrm{~m}$ kum tabakasından oluşmaktadır. Yapılacak dolgu yüksekliği ise $6 \mathrm{~m}$ 'dir. Bahsedilen probleme ait şematik gösterim Şekil 1'de sunulmaktadır. Problem simetrik olduğundan ortadan bölünerek sadece sol yarısı gösterilmiş ve modellenerek çözülmüştür. 


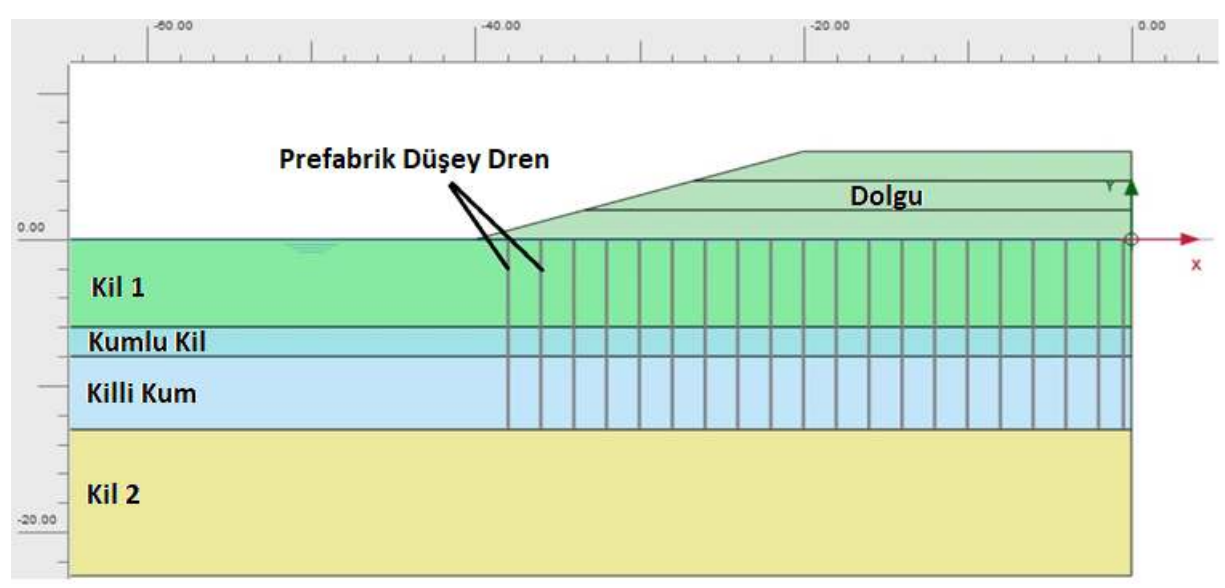

Şekil 1. Dolgu problemine ait şematik gösterim

Modelde kullanılan prefabrik düşey drenlerin uzunlukları $13 \mathrm{~m}$ seçilerek drenler alttaki kum tabakasına kadar uzatılmış ve aralıkları 2 m seçilmiştir.

\subsection{Materyal}

Modellerde yol dolgusu ve temel zeminini oluşturan tabakalar için kullanılan geoteknik parametreler Tablo 1'de verilmektedir.

Tablo 1. Dolgu ve temel zeminine ait malzeme özellikleri

\begin{tabular}{|c|c|c|c|c|c|}
\hline & Kumlu Kil & Killi Kum & Kil 1 & Kil 2 & Dolgu \\
\hline Zemin modeli & $\begin{array}{l}\text { Pekleşen } \\
\text { zemin }\end{array}$ & $\begin{array}{l}\text { Pekleşen } \\
\text { zemin }\end{array}$ & $\begin{array}{l}\text { Pekleşen } \\
\text { zemin }\end{array}$ & $\begin{array}{l}\text { Pekleşen } \\
\text { zemin }\end{array}$ & $\begin{array}{c}\text { Pekleşen } \\
\text { zemin }\end{array}$ \\
\hline Drenaj durumu & Drenajlı & Drenajlı & Drenajsız (A) & Drenajsız (A) & Drenajli \\
\hline $\begin{array}{l}\text { Kuru birim hacim } \\
\text { ağırlık }\left(\gamma_{\text {unsat }}\right)\left(\mathrm{kN} / \mathrm{m}^{3}\right)\end{array}$ & 18 & 17 & 18 & 18 & 19 \\
\hline $\begin{array}{l}\text { Doygun birim hacim } \\
\text { ağırlık }\left(\gamma_{\text {sat }}\right)\left(\mathrm{kN} / \mathrm{m}^{3}\right)\end{array}$ & 20 & 18 & 20 & 19 & 20 \\
\hline $\mathrm{E}_{50}{ }^{\mathrm{ref}}\left(\mathrm{kN} / \mathrm{m}^{2}\right)$ & 8000 & 20000 & 8000 & 12000 & 20000 \\
\hline $\mathrm{c}_{\text {ref }}^{\prime}\left(\mathrm{kN} / \mathrm{m}^{2}\right)$ & 25 & 1 & 25 & 20 & 1 \\
\hline$\emptyset_{\text {ref }}^{\prime}\left({ }^{\circ}\right)$ & 25 & 36 & 25 & 28 & 35 \\
\hline$\psi\left({ }^{\circ}\right)$ & 0 & 6 & 0 & 0 & 5 \\
\hline $\mathrm{k}_{\mathrm{x}}$ (m/gün) & 1 & 1 & 0.0001 & 0.0001 & 1.4 \\
\hline ky (m/gün) & 1 & 1 & 0.0001 & 0.0001 & 1.4 \\
\hline $\mathrm{K}_{0}$ belirleme & Otomatik & Otomatik & Otomatik & Otomatik & Otomatik \\
\hline OCR & 2 & 1.8 & 2 & 1.6 & 2 \\
\hline
\end{tabular}

\subsection{Metot}

Konsolidasyon oturması miktarı, süresi ve oluşan ilave boşluk suyu basınçlarının hesaplanmasında sonlu elemanlar yazılımı olan Plaxis 2D kullanılmıştır. Model "plane strain" olarak tanımlanmış ve 15 düğümlü elemanlar ile sonlu elemanlar ağı oluşturulmuştur. Problemin çözümü için 5 farklı yükleme durumu denenmiş ve bu 5 farklı yükleme durumunun drensiz ve drenli analizleri gerçekleştirilmiştir. Denenen yükleme durumları Tablo 2'de sunulmuştur. 
Tablo 2. Denenen yükleme modelleri

\begin{tabular}{ccccccc}
\hline $\begin{array}{r}\text { Dolgu } \\
\text { Tabaka No }\end{array}$ & \multicolumn{1}{c}{2} & \multicolumn{2}{c}{3} \\
\hline Yükleme & $\begin{array}{c}\text { İnşaat } \\
\text { Süresi } \\
\text { (gün) }\end{array}$ & $\begin{array}{c}\text { Bekleme } \\
\text { Süresi }\end{array}$ & $\begin{array}{c}\text { İnşaat } \\
\text { Süresi } \\
\text { (gün) }\end{array}$ & $\begin{array}{c}\text { Bekleme } \\
\text { Süresi }\end{array}$ & $\begin{array}{c}\text { İnşaat } \\
\text { Süresi } \\
\text { (gün) }\end{array}$ & $\begin{array}{c}\text { Bekleme } \\
\text { Süresi }\end{array}$ \\
\hline 1 & \multicolumn{7}{c}{ Tüm dolgu 1 günde } & inşa ediliyor. \\
2 & 1 & 0 & 1 & 0 & 1 & $\mathrm{P}_{\text {excess }}<1 \mathrm{kPa}$ \\
3 & 1 & 7 gün & 1 & 7 gün & 1 & $\mathrm{P}_{\text {excess }}<1 \mathrm{kPa}$ \\
4 & 1 & 30 gün & 1 & 30 gün & 1 & $\mathrm{P}_{\text {excess }}<1 \mathrm{kPa}$ \\
5 & 1 & $\mathrm{P}_{\text {excess }}<1 \mathrm{kPa}$ & 1 & $\mathrm{P}_{\text {excess }}<1 \mathrm{kPa}$ & 1 & $\mathrm{P}_{\text {excess }}<1 \mathrm{kPa}$ \\
\hline
\end{tabular}

\section{Sonuçlar ve Tartışma}

Sonlu elemanlar analizi ile elde edilen sonuçlar incelendiğinde, drenlerin bulunmadığ durumlarda her kademede boşluk suyu basınçlarının $1 \mathrm{kPa}$ 'a kadar sönümlenmesi beklenirse toplamda en uzun sürenin oluştuğu (839 gün) görülmektedir (Tablo 3). Burada inşaat süresi 3. tabakanın serilmesini de içermektedir. Bu durumda inşaatın tamamlanmasından sonraki konsolidasyon miktarı sönümlenmenin çoğunun inşaat süresinde tamamlanması nedeni ile azalmakta ve $3 \mathrm{~cm}$ ile tüm drensiz çözümler içinde minimum olmaktadır. Maksimum konsolidasyon oturması ise 3 tabakanın birlikte tek seferde yüklendiği durumda $21 \mathrm{~cm}$ olarak meydana gelmektedir (Tablo 3).

Tablo 3. Yükleme durumlarına ait analiz sonuçları

\begin{tabular}{|c|c|c|c|c|c|c|c|c|c|c|c|}
\hline \multirow{2}{*}{\multicolumn{2}{|c|}{$\begin{array}{c}\text { Yükleme Durumu } \\
\text { Dren Durumu }\end{array}$}} & \multicolumn{2}{|c|}{5} & \multicolumn{2}{|c|}{4} & \multicolumn{2}{|c|}{3} & \multicolumn{2}{|c|}{2} & \multicolumn{2}{|c|}{1} \\
\hline & & Drensiz & Drenli & Drensiz & Drenli & Drensiz & Drenli & Drensiz & Drenli & Drensiz & Drenli \\
\hline \multirow{2}{*}{$\begin{array}{l}\text { Süre } \\
\text { (gün) }\end{array}$} & İnşaat & 560.8 & 139.6 & 63 & 63 & 17 & 17 & 3 & 3 & 1 & 1 \\
\hline & Toplam & 839.6 & 187 & 371.8 & 122.7 & 397.4 & 113 & 573.6 & 103.8 & 574.1 & 98.87 \\
\hline \multicolumn{2}{|c|}{$\begin{array}{l}\text { Maksimum Ek Boşluk } \\
\text { Suyu Basıncı }(\mathrm{kPa})\end{array}$} & 37.45 & 38.24 & 69.83 & 39.15 & 95.75 & 49.87 & 105.2 & 96.11 & 106.5 & 104.8 \\
\hline \multirow{2}{*}{ Oturma (m) } & İnşaat & 0.14 & 0.15 & 0.13 & 0.15 & 0.12 & 0.15 & 0.1 & 0.14 & 0.13 & 0.15 \\
\hline & Toplam & 0.17 & 0.17 & 0.18 & 0.17 & 0.17 & 0.17 & 0.19 & 0.18 & 0.21 & 0.21 \\
\hline Güvenlik sayıs & & 2.88 & 2.90 & 2.64 & 2.89 & 2.35 & 2.86 & 2.20 & 2.59 & 2.17 & 2.39 \\
\hline
\end{tabular}

Drenajlı yükleme durumları incelendiğinde, en fazla oturmanın 3 tabakanın birlikte yüklendiği durumda oluştuğu görülmektedir. Buna göre dolgu inşaatı sırasında $15 \mathrm{~cm}$, dolgu tamamlandıktan sonra ilave olarak $6 \mathrm{~cm}$ ve toplamda $21 \mathrm{~cm}$ konsolidasyon oturması oluşmuştur (Tablo 3). Burada dolgunun tamamlanma süresinin kısalmasılya zemin kayma direnci özelliklerine bağlı olarak göçme riskinin artacağı unutulmamalıdır.

Konsolidasyonun tamamlanması için gerekli minimum süre drenlerin bulunmadığı durumlarda 371.8 gün (tabakalar arasında 30 gün bekleme), drenlerin bulunduğu durumlarda ise 98.87 gündür (tek seferde yükleme). Her bir yükleme durumu kendi içerisinde değerlendirildiğinde drenli durumda konsolidasyon süresi 3 tabakanın birlikte yüklendiği durumda \%83, tabakalar arasında 7 gün beklenen yükleme durumunda ise $\% 71$ azalma göstermiştir. 
Güvenlik sayıları hem doğal zeminde hem de prefabrik düşey drenler ile iyileştirilmiş zeminde her dolgu tabakasının inşaatından sonra ilave boşluk suyu basınçları sönümlenene kadar beklenirse 2.9 ile en yüksek değerine ulaşmaktadır. Güvenlik sayıları tabakalar arasında bekleme süresi arttıkça artmakta ve tek seferde yükleme durumunda en düşük güvenlik sayıları elde edilmektedir. (Tablo 3).

Doğal zeminde meydana gelen boşluk suyu basınçları ve sönümlenme süreleri değerlendirildiğinde maksimum boşluk suyu basıncının tek seferde yükleme durumunda oluştuğu, minimum boşluk suyu basıncının ise her tabakadan sonra boşluk suyu basıncının sönümlenmesinin beklendiği yükleme durumunda meydana geldiği görülmektedir (Şekil 2).

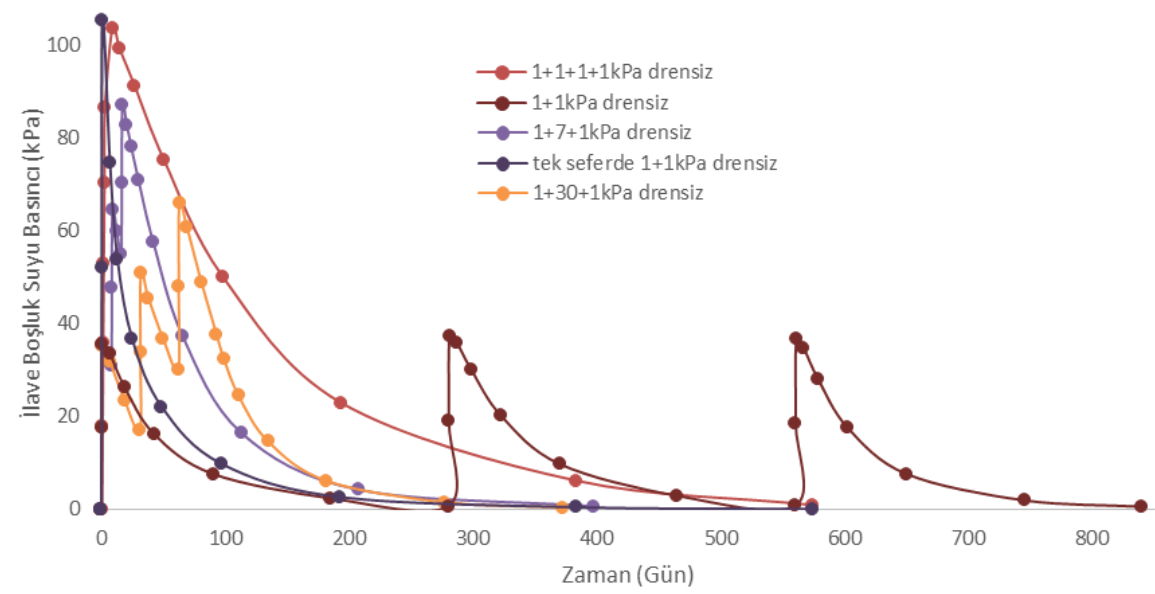

Şekil 2. İyileştirilmemiş doğal zeminde farklı yükleme durumlarında meydana gelen ilave boşluk suyu basınçları

Prefabrik düşey drenler ile iyileştirilmiş zeminde meydana gelen ilave boşluk suyu basıç̧ları incelendiğinde tek seferde yükleme ve tabakalar arasında hiç beklenmeden 3 tabakanın ardı ardına yüklendiği durumlarda ilave boşluk suyu basınçlarının drensiz durumdaki maksimum seviyelere ulaştı̆̆ 1 , diğer durumlarda ise maksimum basınçların düşük seviyelerde kaldığı görülmektedir (Şekil 3).

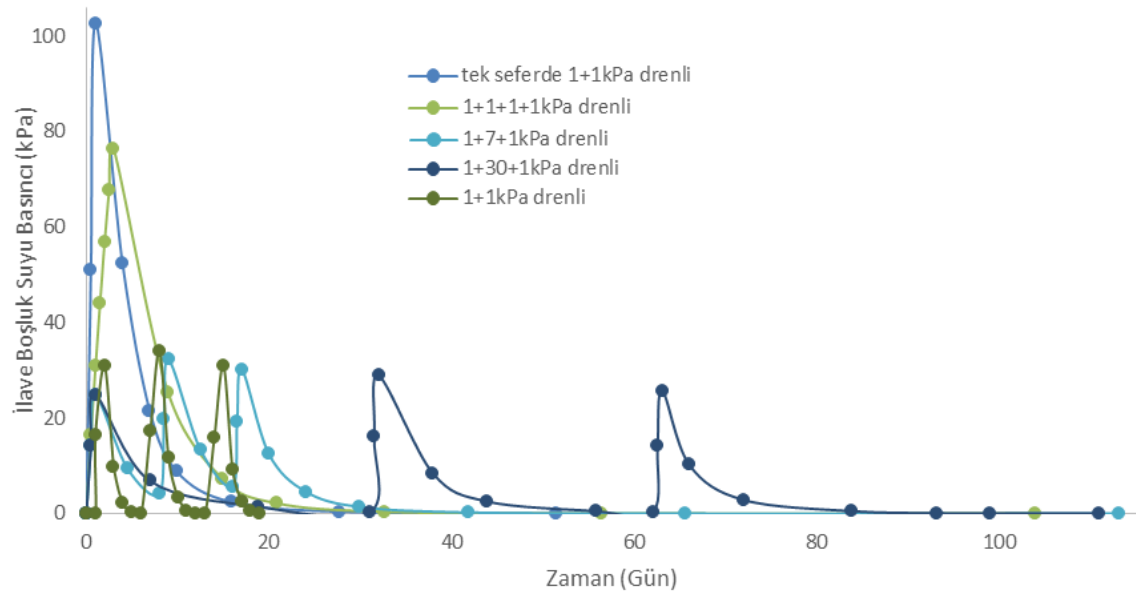

Şekil 3. Drenler ile iyileştirilmiş zeminde farklı yükleme durumlarında meydana gelen ilave boşluk suyu basınçları 


\section{Sonuç}

Çalışma kapsamında doğal zemin ve prefabrik düşey drenler ile iyileştirilmiş zeminde farklı yükleme durumlarında sonlu elemanlar analizi ile konsolidasyon süreleri, ilave boşluk suyu basınçları, oturmalar ve güvenlik sayıları hesaplanmıştır. Buna göre;

a) Drensiz durumda drenli duruma göre yükleme adımlarında daha fazla ilave boşluk suyu basınçları oluşmakta ve sönümlenme için çok daha fazla zamana ihtiyaç duyulmaktadır.

b) Drenli ve drensiz durumda dolgunun tek seferde yapılması ile toplam konsolidasyon miktarı artmaktadır. Bu durum, özellikle drensiz durumlarda kayma direnci düşük zeminlerde dolgu tamamlanmadan göçmeye yol açabilir.

c) Dren kullanılması yükleme durumuna bağlı olarak konsolidasyon süresini $\% 70-\% 85$ oranında azaltmaktadir.

d) Göçmeye karşı güvenlik sayıları hem doğal zeminde hem de prefabrik düşey drenler ile iyileştirilmiş zeminde dolgu tabakalarının inşaasından sonra geçen bekleme süresinin artmasıyla artmaktadır. Güvenlik sayıları drenli durumda drensiz duruma göre yüksek çıkmaktadır.

\section{Kaynaklar}

[1] Borges JL. Three-dimensional analysis of embankments on soft soils incorporating vertical drains by finite element method. Computers and Geotechnics 2004; 31:665-676.

[2] Jamiolkowski M, Lancellotta R, Wolski W. Pre-compression and speeding up consolidation, general report. Special Session 6, Proceedings of Eight European Conference on Soil Mechanics and Foundation Engineering. Balkema, Rotterdam, 1983; 1201-1226.

[3] Rixner JJ, Kraemer SR, Smith AD. Prefabricated vertical drains. Engineering Guidelines, FWHA/RD86/168, Federal Highway Administration. Washington DC, 1986, vol. 1.

[4] Chai JC, Miura N, Zhu HH, Yudhbir S. Compression and consolidation characteristics of structured natural clay. Canadian Geotechnical Journal 2004; 41:12:1250-1258.

[5] Holtz RD, Shang JQ, Bergado DT. Soil improvement. Geotechnical and Geoenvironmental Engineering Handbook. Kluwer Academic Publishing, Norwell, USA, 2001; 429-462 (Chapter 15).

[6] Hansbo S. Consolidation of fine-grained soils by prefabricated drains. Proceedings of the Tenth International Conf. on Soil Mechanics and Foundation Engineering. Stockholm, 1981; 3:677-682.

[7] Bergado DT, Anderson LR, Miura N, Balasubramaniam AS. Soft Ground Improvement, in Lowland and other Environments. ASCE Press, 1996; 427.

[8] Shen S-L, Chai J-C, Hong Z-S, Cai F-X. Analysis of field performance of embankments on soft clay deposit with and without PVD-improvement. Geotextiles and Geomembranes 2005; 23:463-485.

[9] Lo SR, Mak J, Gnanendran CT, Zhang R, Manivannan G. Long-term performance of a wide embankment on soft clay improved with prefabricated vertical drains. Canadian Geotechnical Journal 2008; 45:1073-1091. 